\title{
MeHarCEn: Um Método de Harmonização do Consumo de Energia em Data Centers
}

\section{MeHarCEn: A Method of Harmonizing Energy Consumption in Data Centers}

\author{
Daniel Scheidemantel Camargo ${ }^{1}$ \\ Charles Christian Miers ${ }^{1}$ \\ Maurício Aronne Pillon ${ }^{1}$ \\ Guilherme Piegas Koslovski ${ }^{1}$
}

Data de submissão: 13/09/2017, Data de aceite: 12/11/2017.

\begin{abstract}
Resumo: O consumo energético controlado e eficiente é um desafio enfrentado diariamente pelos gestores de Data Centers (DCs) de pequeno, médio e grande porte. A literatura especializada e técnica define diversos guias, equipamentos e mecanismos para essa finalidade. Entretanto, a aplicação combinada dessas soluções é uma tarefa complexa, que, em muitos casos, requer um elevado investimento financeiro. Nesse contexto, o presente trabalho propõe MeHarCEn, uma iniciativa para gerenciamento combinado e harmônico do consumo de energia em DCs. MeHarCEn não depende de soluções proprietárias e pode ser adaptado a DCs com configurações distintas. Aplicado a um estudo de caso, em um DC de pequeno porte, o MeHarCEn resulta em uma economia de $52,7 \%$ no consumo de energia com climatização.
\end{abstract}

\begin{abstract}
Controlled and efficient power consumption is a challenge faced daily by small, medium, and large data center (DC) administrators. Specialized and technical literature defines several guides, equipment, and mechanisms for this purpose. However, the combined application of these solutions is a complex task, which in several cases implies on high financial investment. In this context, we present MeHarCEn, a method for combined and harmonic management of energy consumption in DCs. MeHarCEn does not depend on proprietary solutions and can be adapted on DC's based on different configurations. Applied to a case study, a small DC, MeHarCEn results in a savings of $52.7 \%$ in energy consumption with air conditioning.
\end{abstract}

Palavras-chave: Data centers, eficiência energética, gerenciamento de data center.

Keywords: Data centers, energy efficiency, data center management.

\section{Introdução}

O crescente volume de processamento de dados produzido por novos paradigmas, como a computação em nuvem, traz constantes desafios para as organizações que abrigam uma infraestrutura de

\footnotetext{
${ }^{1}$ Programa de Pós-Graduação em Computação Aplicada - PPGCA, Universidade do Estado de Santa Catarina - UDESC, Rua Paulo Malschitzki, 200, Campus CCT - Joinville (SC) - Brasil

\{daniel@colmeia.udesc.br\}, \{charles.miers, mauricio.pillon, guilherme.koslovski\}@udesc.br
} 
DC [1, 2]. Estudos apontam uma tendência de expansão dos DCs em quantidade e tamanho para os próximos anos [3] devido a necessidade de acompanhar a alta demanda do exigente mercado de Tecnologia da Informação (TI). Um destes desafios está relacionado ao consumo de energia elétrica que impacta restritivamente e indiretamente na sua expansão [4]. Estima-se que até 2011, os DCs tenham sido responsáveis por aproximadamente $2 \%$ do consumo energético mundial [5] e atualmente projeta-se um aumento de 53\% deste percentual até 2020 [6]. Essa projeção remete a dois desafios: a necessidade de melhorias na grade energética atual para suprir a esta demanda e o desenvolvimento de novas abordagens que possibilitem reduzir ou desacelerar esta demanda energética.

Estas tendências despertam o interesse dos gestores de DC, principalmente quando trata-se de reduzir os custos operacionais com energia elétrica em sua infraestrutura através de abordagens energeticamente eficientes, e também de fomentar a sustentabilidade ambiental em suas atividades [7]. Mesmo com o desenvolvimento de soluções e métodos que permitam obter a eficiência energética em DCs [8,9], normalmente a sua implementação não está publicamente disponível, o que inviabiliza colocá-los em prática. Um exemplo disso é a norma International Organization for Standardization (ISO) 50001 [10], que consiste em uma ferramenta proprietária para aplicação e gestão de eficiência energética, mas possui um considerável custo de implantação. As despesas com energia elétrica em um DC podem corresponder a até 50\% dos seus custos operacionais [11]. Neste sentido, a redução de custos com este insumo permite compensar os investimentos aplicados em melhorias da infraestrutura, como a renovação de ativos por equipamentos mais eficientes e aquisição de sistemas de monitoramento. Ainda assim, o custo de colocar em prática um Programa de Eficiência Energética (PEE) não é atrativo para pequenas e médias organizações devido à expectativa de baixo impacto em sua produção, segundo pesquisa do Uptime Institute [12]. Já em organizações de médio a grande porte, a distância entre o departamento operacional e financeiro dificulta a sua cooperação para ações energeticamente eficientes [13]. Enquanto não há aporte financeiro para a parte operacional, o financeiro desconhece as boas práticas de eficiência energética em um ambiente de DC.

Existem atualmente ferramentas específicas para gerenciar a eficiência energética em uma organização, bem como documentos que listam as políticas de eficiência energética $[14,15]$ fomentando as boas práticas pelos gestores. Porém, normalmente, estas abordagens podem ser demasiadamente complexas, pois normalmente não há o conhecimento necessário para desenvolver um PEE de modo consistente, visando uma execução continuada. Diante dessa motivação, o objetivo do presente trabalho é apresentar o método de harmonização para o consumo de energia (MeHarCEn), que consiste em uma aplicação sistemática das boas práticas para DCs, visando a eficiência energética da infraestrutura, combinada com a redução de custos operacionais com energia elétrica e do impacto ambiental. Um método de harmonização permite que as ações sejam mensuráveis, e com isso, leva a obtenção de resultados comparáveis entre diferentes procedimentos. Assim, o MeHarCEn é concebido com base em quatro características: (i) ser um método sistemático; (ii) ser específico para DCs; (iii) ser de baixa complexidade de implantação; e (iv) ser de baixo custo de implementação.

Constituído por duas fases principais decompostas em etapas, o MeHarCEn guia o gestor para o desenvolvimento de um PEE seguindo as normas técnicas e métricas estabelecidas pela indústria de equipamentos e infraestrutura de DC. Deste modo, o MeHarCEn possibilita por em prática diversas políticas de eficiência energética, ao mesmo tempo em que obtém informações consistentes, compatíveis com os padrões internacionais, permitindo a geração de relatórios e o acompanhamento dos ganhos com eficiência a longo prazo. Ainda, o presente trabalho evidencia que as oportunidades de redução de despesas operacionais com energia elétrica podem ser discutidas sob a perspectiva da eficiência energética através da adoção de boas práticas, que, aplicadas de forma continuada, resultam em economia financeira e na redução do impacto ambiental.

O artigo está organizado em seções da seguinte forma: na Seção 2 são apresentados os trabalhos 
correlatos, seguidos pela descrição do método proposto, Seção 3; A discussão dos resultados bem como a especificação do componentes do estudo de caso real encontram-se na Seção 4; e, finalmente, na Seção 5 são apresentadas as considerações finais e as perspectivas para trabalhos futuros.

\section{Métodos correlatos para harmonização do consumo de energia em DCs}

A grande maioria das abordagens isoladas que buscam auxiliar na redução do consumo de energia $[16,8,9]$ são específicas a aplicações. O método proposto é mais amplo, pois considera todos os componentes do DC, possibilitando a aplicação de um conjunto maior de técnicas que permitam a redução do consumo de energia. Neste contexto, após pesquisa exploratória, os dois trabalhos relacionados que se destacaram por visarem a redução contínua do consumo de energia para o DC de forma holística, foram: Laboratório Nacional Lawrence Berkeley (LBNL) e a Norma ISO 50001. Ambas as abordagens fornecem ao gestor uma maior consistência para aplicar as políticas de eficiência energética e mensurar o impacto das ações adotadas, permitindo comparar estes resultados de forma consistente.

\subsection{Ferramentas do LBNL}

Com foco específico na monitoração e possível redução do consumo de energia de DCs, o LBNL 2 e o Department of Energy (DoE) dos Estados Unidos da América (EUA), somaram esforços para desenvolver um conjunto de ferramentas que atuam desde a identificação do perfil energético do DC até a determinação de listas de políticas de eficiência energética. São disponibilizadas oito ferramentas, destacando-se:

1. DC Pro: ferramenta web para o levantamento do perfil energético do DC, estima o PUE e aponta possíveis melhorias;

2. Energy Assessment Process Manual: treinamento e instruções para gestão de eficiência energética;

3. Energy Assessment Worksheets: planilha para documentar métricas, ações e medidas de avaliação do DC;

4. Energy Assessment Kit Guide and Specification: estabelece o desenvolvimento de um kit temporário de medição do consumo de energia;

5. Data Center Air Management: planilha com recomendações de gerenciamento de equipamentos de refrigeração;

6. Data Center Electrical Power Chain: planilha com recomendações para a distribuição e armazenamento de energia elétrica;

7. Energy Efficiency Assessment Report Template: modelo de relatório para registar os resultados obtidos; e

8. Data Center Master List of Efficiency Actions: compreende uma lista com as as políticas de eficiência energética para DCs.

Os responsáveis pelo LBNL não se preocuparam com a forma de aplicação destas ferramentas, tanto pouco com a adequação a outras categorias de DC. Embora não haja indicação de um método ou de uma ordem de aplicação destas ferramentas, a organização do pacote de ferramentas leva a maioria dos usuários a seguir a sua orientação numérica, iniciando com DC Pro (item 1) e finalizando com Data

${ }^{2}$ Disponível em: <https://datacenters.lbl.gov/tools> 
Center Master List of Efficiency Actions (item 8). Supondo que o usuário tenha seguido a ordem implicitamente sugerida pelos desenvolvedores, a ausência de um método, ou mesmo de um mecanismo sistemático de aplicação das ferramentas, certamente, mitigam a eficiência da aplicação das ferramentas. A maximização dessa eficiência exige conhecimento aprofundado do usuário que deve identificar a necessidade de: (i) adequação dos parâmetros; (ii) reaplicação continua de uma determinada ferramenta; ou (iii) iteração de um subconjunto de ferramentas. No entanto, a maior restrição da ferramenta não é a necessidade de um usuário especialista, mas sim, o conhecimento específico de características geográficas regionais. DC Pro, primeira ferramenta do pacote, exige do usuário dados como zona termal e código postal, ambos específicos dos EUA, excluindo, sumariamente, o uso da ferramenta em outra região. Os autores deste trabalho não se preocuparam com o estudo de viabilidade da adaptação da ferramenta a outras regiões, pois esta ação está fora do escopo deste trabalho. Finalmente, a aplicação do pacote de ferramentas do LBNL tem por objetivo a geração de resultados a pesquisas do próprio LBNL, de certo modo, explicando a ausência de um método público de aplicação do pacote ou a restrição das regiões de observação.

\subsection{Norma ISO 50001}

A norma ISO 50001 [10] estabelece a padronização de um Sistema de Gestão Energética (SGE) para organizações que desejam desenvolver, implementar e melhorar sua eficiência energética, baseada em uma abordagem sistemática de melhoria contínua do desempenho. Esta norma usa o framework Plan-Do-Check-Act (PDCA) [17], que consiste em um ciclo de melhorias contínua constituída por quatro fases distintas. A Figura 2.2 indica nos círculos com as letras PDCA em cada etapa do processo. (i) P: planejamento (etapas de política energética e planejamento de energia); (ii) D: execução (etapa de implementação e operação); (iii) C: verificação (as três etapas do ciclo de verificação); e (iv) A: ação (etapa de revisão pela gestão). Este ciclo repete-se continuamente em cada nova fase de planejamento, possibilitando abranger diversas áreas da organização. A fase de planejamento trata das políticas energéticas e planejamento do consumo de energia para todos os componentes de uma organização, independente do setor de atuação, considerando desde equipamentos fabris até DCs. O Ciclo PDCA também tem sua aplicabilidade no presente trabalho, com suas quatro etapas identificadas na Figura 2 da Seção 3.

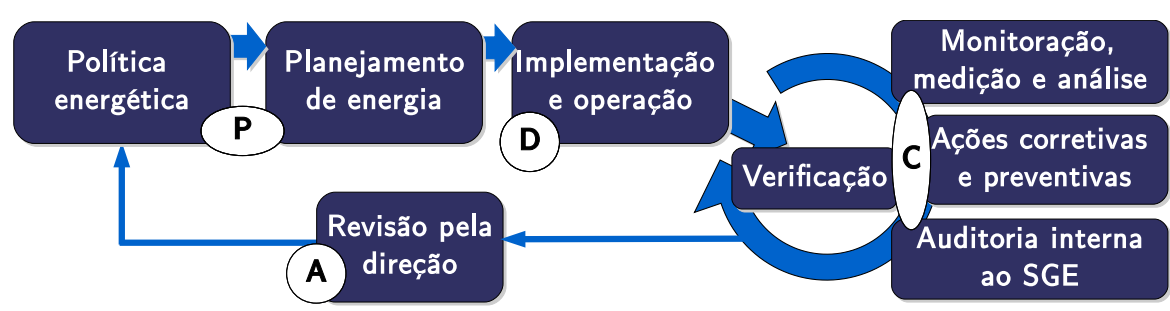

Figura 1. Ciclo PDCA da norma ISO 50001. Adaptado de [18].

Para obter uma certificação oficialmente reconhecida pela ISO, a instituição a ser certificada deve buscar uma entidade homologadora licenciada pela ISO [19] para a norma 50001. Inicialmente, é realizado um contrato de acompanhamento técnico qualificado para implementação do SGE, bem como esforços posteriores para capacitar a equipe responsável pela continuidade do SGE ao manter a certificação. O conjunto de exigências para a certificação ISO acaba acarretando em altos custos de implantação e manutenção para longo prazo. Em pesquisa realizada em 2013 [20], indica que, o custo total por instalação é de U\$319.000,00 em média, que com variação entre U\$207.000 e U\$498.000, dependendo do tamanho da organização, da quantidade de colaboradores envolvidos e da capacitação especializada a ser 
contratada. No Brasil, não há estudos que indiquem os custos relacionados à implementação da Norma ISO-50001.

A adoção da Norma ISO 50001 em ambientes de DCs tem custos compatíveis com organizações gestoras de DC de grande porte, porém inviabiliza sua implantação em pequenas e médias organizações, principalmente, devido a restrições financeiras [12]. No entanto, a ausência de políticas específicas para ambientes de DCs é um fator limitante para a adoção da Norma ISO 50001 por todas as organizações gestoras de DCs. As políticas genéricas e com altos níveis de abstração propostas pela Norma ISO 50001, têm o intuito de englobar o maior número de organizações e de setores mais variados, porém, exigem do gestor maior conhecimento das normas e de limiares e, sobretudo, dedicação do corpo técnico. $\mathrm{Na}$ ausência de opções mais adequadas às suas necessidades, organizações gestoras de DCs de grande porte acabam adotando a Norma ISO 50001, enquanto organizações de pequeno e médio portes ficam sem acesso a ferramentas de gestão energética ou de como implementarem seu próprio PEE.

\subsection{Considerações sobre os métodos correlatos}

A proposta do LBNL e da Norma ISO 50001 foram selecionadas em pesquisa exploratória exaustiva em meios científicos e corporativos, destacando-se como soluções para gestão de eficiência energética em ambientes de DCs com documentação suficiente para sua análise. Enquanto as ferramentas do LBNL tem objetivos específicos a um determinado ambiente (DCs), a Norma ISO 50001 tem um alto nível de abstração devido ao seu propósito geral. Mesmo com objetivos similares, sua aplicabilidade são para ambientes e organizações diferentes, o que dificulta uma análise sob critérios objetivos, e.g., comparar qual a margem de eficiência entre as ferramentas. Deste modo, habilita-se destacar quatro características relacionadas à implementação destas ferramentas, subjetivamente atribuídos os valores 'alto' e 'baixo' . Uma pesquisa complementar realizada em literatura científica especializada em normas e ferramentas relacionadas à gestão energética [21, 22, 23, 24], reforçam estas quatro características como as relatadas pelas organizações que implementam estas ferramentas. Estas características são:

A complexidade de implantação de uma ferramenta em uma organização também está relacionada às suas características de sistematização e sua implantação autossuficiente, explanadas em sequência. Um alto grau de complexidade refere-se à uma ferramenta estar especificada em conceitos abstratos visando sua implantação em diversos segmentos de negócios, com seus equipamentos específicos e corpo técnico. Um baixo grau de complexidade concerne a uma especificação mais clara e objetiva dos conceitos relacionados à ferramenta, coerentes com um determinado segmento de negócios ou tipo de organização. Embora o alto grau de complexidade permita aplicar a mesma ferramenta em diversos segmentos, isso cria maior dependência de conhecimentos específicos, havendo uma necessidade de traduzir, muitas vezes erroneamente, estes conceitos. Assim, quanto maior o grau de abstração do método, maior a complexidade da implantação deste método, e maior a necessidade de conhecimento específico por parte da equipe que implementará a ferramenta, bem como dos gestores do DCs. Neste quesito, baseado em [21], o melhor resultado é aquele que determine baixo grau de complexidade.

O custo financeiro representa a soma total dos custos com implantação (e.g., equipamentos especializados de monitoração e treinamento de corpo técnico), implementação (certificação, políticas que exigem investimento) e manutenção (renovação de certificação) necessárias para a aplicação contínua do PEE. Uma vez que qualquer ferramenta de gestão energética demandarão custos em comum, neste critério são contabilizados apenas valores vinculados às itens específicos. Um alto custo financeiro é aquele caracterizado pela indispensável necessidade de itens específicos, como exigência de treinamentos especializados, auditoria externa, (re)certificação e ferramentas proprietárias de gestão. Um baixo custo financeiro está relacionado à ausência ou minimização da exigência destes itens específicos, permanecendo itens como equipamentos de monitoração, políticas que exigem investimento (e.g., troca de 
equipamentos legados por novos mais eficientes), e horas de trabalho para reuniões de treinamento interno. Embora o rigor exigido por uma certificação permita obter níveis maiores de eficiência energética para algumas organizações, habilitando um retorno sobre investimento (ROI) mais rapidamente, a grande parte das organizações, principalmente de pequeno a médio porte, ainda que não possuem a cultura de investir em eficiência [12], o que pode afastar a adoção de ferramentas de gestão energética. Esta características é baseada em [12, 21, 24], onde o melhor resultado é aquele que determina um baixo custo financeiro.

O método sistemático é um critério relacionado a melhoria continuada, pois além da própria aplicação de políticas exigir uma sistematização para sua implementação, a continuidade desta política deve fazer parte das atividades da organização. Ferramentas de gestão baseadas em métodos sistemáticos impedem que as suas etapas sejam isoladamente utilizadas ou interpretadas, exigindo-se que todo o conjunto seja analisado e executado. A cada etapa que se atinjam resultados, estes servem como entradas nos passos subsequentes e com a evolução do processo, aprofunda-se a aprendizagem sobre uma determinada situação de interesse. Este quesito está relacionado com a implementação prática, tanto do próprio PEE, quanto das políticas que são continuamente implementadas. Assim, um alto grau de sistematização indica que a ferramenta de gestão ou PEE possui uma sistematização e, portanto, se adapta mais facilmente às atividades perenes. Por outro lado, um baixo grau de sistematização exige que a própria organização tenha que desenvolver sua metodologia, demandando dedicação específica do corpo técnico. Esta característica é baseada em [24, 23], e seu melhor resultado é aquele que determine alto grau sistêmico.

A aplicação autossuficiente está relacionada com a capacidade da ferramenta em permitir que o próprio corpo técnico, formado por colaboradores da organização, tenha a possibilidade de implementá-la na prática, além de manter continuamente em execução as políticas já implementadas. Inerentemente, organizações são formadas por colaboradores que constituem o corpo técnico em determinados segmentos, capacitados para áreas de atuação distintas e complementares entre si, onde o conhecimento gerado na organização para fornecimento de seus serviços não está concentrado em uma única pessoa. Isso permite que as próprias organizações tenham a possibilidade de implementarem o seu PEE. Um alto grau de aplicação autossuficiente de uma ferramenta de gestão indica que sua aplicabilidade deve ser de fácil compreensão, minimizando a margem de interpretações errôneas. Um baixo grau de aplicação autossuficiente é inerente de soluções proprietárias, que demandam em contratação de treinamento específico para dar suporte ao implementar o PEE. Assim, a presente característica baseada em [22], indica que o melhor resultado é aquele que determine um alto grau de aplicação autossuficiente.

Tabela 1. Comparação entre LBNL e a Norma ISO 50001.

\begin{tabular}{|l|c|c|}
\hline Características & LBNL & ISO 50001 \\
\hline \hline Complexidade de aplicação & Baixo & Alto \\
\hline Custo financeiro & Baixo & Alto \\
\hline Método sistemático & Baixo & Alto \\
\hline Aplicação autossuficiente & Alto & Baixo \\
\hline
\end{tabular}

Os resultados da análise dos métodos correlatos segundo as características básicas aplicáveis a ambientes de DCs encontram-se na Tabela 1. As células hachuradas indicam que o trabalho adequa-se a categoria desejada (alto ou baixo). Pode-se constatar, que nenhum dos trabalhos analisados cumprem as quatro características do contexto estudado. O pacote de ferramentas da LBNL enquadra-se em três das quatro características, enquanto, a Norma ISO 50001 identifica-se somente em uma. É importante ressaltar que a aplicabilidade geográfica global não foi levada em consideração, um fator que restringe o uso da ferramenta LBNL fora do EUA. Neste contexto, o levantamento bibliográfico e a análise de suas características indicam uma área de atuação em aberto, onde a aplicação contínua da eficiência energética 
em DCs, em que a própria equipe de TI possa implementar as boas práticas com baixo custo financeiro e complexidade, não é fornecida por nenhuma ferramenta ou método documentado até o momento.

\section{Método de harmonização MeHarCEn}

O método proposto para harmonização do consumo de energia, denominado MeHarCEn, consiste em uma sequência de etapas organizadas de forma sistemática, que visam orientar a aplicação autossuficiente de diversas políticas de eficiência energética. Do mesmo modo que no método científico [25], esta sistemática é importante para que a redução do consumo de energia nos diversos sistemas do DC seja igualmente mensurável e consistentemente comparável. Isso permite que os resultados obtidos possam ser devidamente analisados e documentados permitindo acesso à organização como um todo. A possibilidade de gerar relatórios consistentes para cada uma das ações fomenta não apenas o conhecimento e as habilidades adquiridas entre os colaboradores da organização, mas uma ferramenta para reportar aos clientes e parceiros a responsabilidade sobre o consumo de recursos energéticos. Assim, o MeHarCEn é concebido para suprir a demanda de um método de livre aplicação e replicação, que permita ao gestor adequá-lo às necessidades intrínsecas de sua organização, através de uma sequência de etapas sistematicamente organizadas. Quando se implementa o MeHarCEn na prática, com uma determinada política de eficiência energética, denomina-se que um PEE está em execução.

Aplicar o MeHarCEn não exige custos com certificação, ao mesmo tempo em que é possível obter um comportamento similar aos métodos correlatos, como a ISO-50001. Embora o presente trabalho não possua a mesma estrutura e abrangência de normas ISO, pode ser considerada como uma opção viável por fomentar a responsabilidade ambiental sistematicamente. Esta similaridade é possível devido a adequação do método proposto ao protocolo International Performance Measurement and Verification Protocol (IPMVP) [26], que também é utilizado pela Norma ISO 50001. IPMVP consiste em um conjunto de termos e boas práticas, que visam padronizar e quantificar os resultados sobre eficiência de uso de recursos naturais, como a energia elétrica, possibilitando uma maior confiabilidade na interpretação dos dados coletados [27]. O protocolo está organizado em quatro opções de medição e avaliação $(A, B$, $C$ e $D$ ), adequadas às características de cada PEE [28]. Estas opções são divididas em dois métodos base: medição isolada $(A$ e $B)$ e medição de toda a instalação $(C$ e $D)$. Na medição isolada, a opção $A$ é considerada mais simples e de menor custo, mas com maior margem de erro, pois consiste em mensurar apenas um parâmetro chave (e.g., potência) do sistema em questão, estimando-se os demais parâmetros (e.g., horas de funcionamento). A opção $B$ é considerada mais complexa e custosa, mas provê uma menor margem erro, pois consiste em mensurar todos os parâmetros relativo ao sistema. Quando a medição é realizada em toda a instalação, a opção $C$ caracteriza-se por demandar uma maior quantidade e variedade de dados, tanto no período de referência anterior, como no período de execução da ação. Por fim, a opção $D$ consiste em realizar uma simulação calibrada, útil quando não há dados no período de referência, assim os dados devem ser estimados sob experimentos controlados, e.g., em simulação dinâmica de edifícios. Estas quatro opções podem caracterizar uma determinada PEE de acordo com a disponibilidade de monitoração.

De modo geral, o MeHarCEn é dividido em duas fases distintas: (i) Fase Preparatória e (ii) Fase de Aplicação. A Fase Preparatória (Figura 2.I) é constituída por um conjunto de seis etapas e deve ser executada no início da implementação do PEE em uma organização. É nessa fase que são realizadas as principais definições, além do estudo das políticas de eficiência a serem implementadas. Estas seis etapas são descritas da seguinte forma:

(a) Responsáveis: Definição dos indivíduos responsáveis, que consistem em um grupo multidisciplinar de pessoas comprometidas com os objetivos do PEE, também denominado de corpo técnico do 
PEE;

(b) Orçamento: Algumas etapas e políticas necessitam de investimentos, mesmo que contraditório, pois o objetivo é reduzir custos, portanto deve-se definir o orçamento estimado para a implementação do PEE;

(c) Descrição dos equipamentos: Neste momento é feito o levantamento do perfil energético em todos os equipamentos do DC, importante para encontrar os pontos críticos e indicar as possíveis melhorias;

(d) Levantamento das políticas: Deve ser realizado um estudo prévio das listas de políticas de eficiência energética (definição na Seção 3.1), para conhecer as boas práticas e correlacionar com os equipamentos existentes no DC;

(e) Seleção das políticas: Selecionar uma lista das políticas de eficiência possíveis de serem implementadas, analisadas com base no orçamento e nos equipamentos existentes; e

(f) Aplicação das políticas no MeHarCEn: Aplicar individualmente as políticas selecionadas na etapa (e), organizadas em ordem de prioridade por critério de ganho de eficiência energética ou por complexidade de implementação.

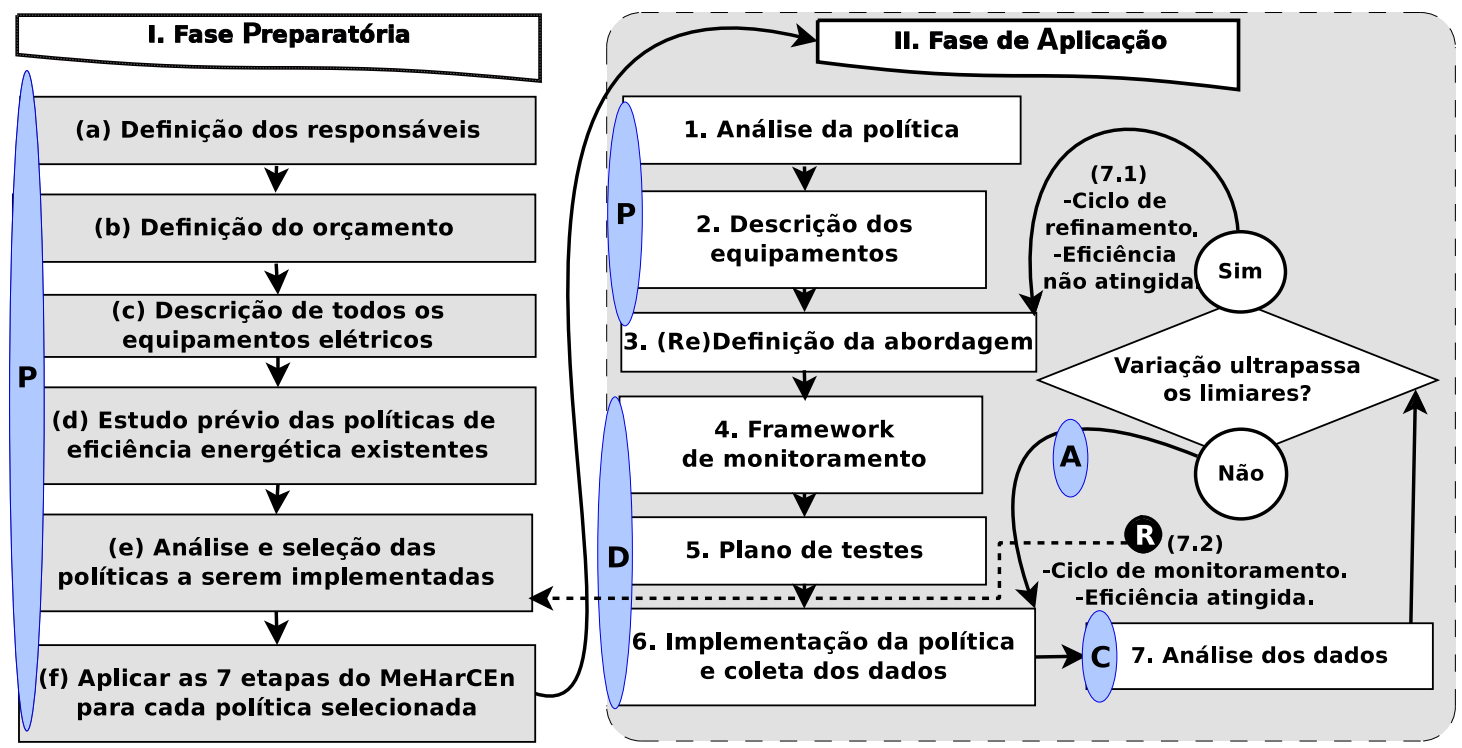

Figura 2. Fluxograma geral para o método proposto MeHarCEn em duas fases: (I) Fase Preparatória (etapas de $a$ a $f$ ); e (II) Fase de Aplicação (etapas de 1 a 7).

Para possibilitar que o PEE tenha um histórico evolutivo documentado, no caso de alterar as informações definidas na Fase Preparatória, esta deverá ser adicionada como um novo versionamento e não substituída. Esta é uma boa prática de gerência de projeto, para manter a rastreabilidade da evolução e refinamento de requisitos. É com base nesta Fase Preparatória do método, que é executada a Fase de Aplicação das políticas selecionadas, pois estas informações são utilizadas durante todo o PEE.

Na segunda parte, a Fase de Aplicação consiste em uma sequência de sete etapas que são aplicadas em cada uma das políticas selecionadas. Na Figura 2.II, cada retângulo corresponde a uma etapa 
do MeHarCEn e o losango representa a questão de decisão sobre a etapa de análise dos dados, possibilitando seguir por uma das respostas: o ciclo de refinamento (7.1) para redefinir a abordagem e o ciclo de monitoramento (7.2) quando a eficiência desejada é alcançada. Estas etapas são:

1. Análise: Analisar com profundidade a política a ser colocada em prática, através de normas, métricas e limiares dos parâmetros a serem monitorados.

2. Descrição: Levantar os equipamentos correlacionados à política selecionada, podendo basear-se no item (c) da Etapa (I).

3. (Re)definição: Efetuar a execução prática da política de eficiência com as devidas alterações nos equipamentos/sistemas (podem ser utilizadas técnicas de gestão de projeto).

4. Monitoramento: Definição do sistema de monitoramento, com base nos parâmetros e objetivos selecionados. Nesta etapa são definidos os sensores para obter as informações desejadas.

5. Testes: Planejamento dos testes para definir: prazos de implantação, locais de observação, período de duração do monitoramento, etc.

6. Implementação: Efetiva aplicação da política (conforme etapa 3) e coleta dos dados (conforme etapa 5). A análise dos dados pode ser realizada em tempo de operação.

7. Análise: Análise geral da variabilidade dos dados para verificar a continuidade da política atual. A resposta pode indicar um retorno para a etapa 3, gerando o ciclo de refinamento (7.1), ou, se os dados estão em conformidade com os limiares especificados, direcionando para o ciclo de monitoramento (7.2), mantendo-se a coleta de dados (etapa 6).

Após a implementação de cada política, deve-se mensurar a eficiência obtida, comparando o consumo anterior com o consumo atual. Por fim, gerar o relatório final para a nova política bem-sucedida é importante para a documentação do PEE. O objetivo é aplicar diversas políticas consecutivas à medida em que são finalizadas de forma bem-sucedidas, i.e., quando permanecem no ciclo de monitoramento (7.2). Assim, do ciclo 7.2 deve-se iniciar a Fase de Aplicação (II) com a próxima política previamente listada na etapa (e) da Fase Preparatória (I) (seta 'R' tracejada), mantendo-se sempre em prática as políticas já implementadas. A execução iterativa de um PEE baseado no MeHarCEn em uma organização possibilita que políticas diversificadas sejam implementadas e que a eficiência energética seja atingida em diversos sistemas do DC. O PEE deve ser mantido continuamente em execução, mesmo depois de serem implementadas todas as políticas, sendo mantidas em um processo (ciclo) de refinamento e manutenção. Adicionalmente, na Figura 2 também estão identificadas as quatro fases do ciclo PDCA, sendo relacionadas como:

(i) Planejamento (P): todas as seis etapas da Fase Preparatória (I), além das etapas de 1 a 3 da Fase de Aplicação (II));

(ii) Execução (D): das etapas de 4 a 6 na Fase de Aplicação (II));

(iii) Verificação (C): etapa 7, com a questão de decisão, se alcançou a eficiência desejada e retorna para ciclo atual (7.1) e adiciona uma nova política ou se mantém em refinamento (7.2); e

(iv) Ação (A): Após ciclo de refinamento 7.2 e reportados os dados com as as atividades realizadas é que os gestores e diretores certificarão que a política se manterá em execução, retornando para o Planejamento $(\mathrm{P})$ através da seta ' $\mathrm{R}$ ' tracejada.

Uma vez descrita a Fase Preparatória, as próximas subseções focam no detalhamento das etapas da Fase de Aplicação. 


\subsection{Análise da política de eficiência energética}

As políticas de eficiência energéticas (doravante políticas) constituem um conjunto de regras de alto nível de especificação, que estabelecem boas práticas de uso dos equipamentos e sistemas relacionados e objetivam obter a redução do consumo de energia elétrica. Os níveis de especificação destas políticas podem variar conforme o setor da organização, a atividade fim e os tipos de equipamentos (e.g., políticas para metalúrgicas, para indústrias de linha de montagem e para DCs). Especificamente em DCs, existem duas listas de políticas que podem ser inicialmente destacadas: DC Master List of Energy Efficiency Actions $^{3}$ (uma das ferramentas do LBNL); e a europeia Best Practice Guidelines for the European Union Code of Conduct on Data Centre Energy Efficiency ${ }^{4}$. Ambas as listas destacam-se devido a revisão periódica por grupos de trabalhos composto por especialistas na área de DC.

Na presente etapa, a política selecionada na Fase Preparatória deve ser analisada com informações extras às definidas na lista de políticas. Como principais informações adicionais, destacam-se as normas e as métricas a serem usadas para verificar a eficiência obtida. As normas definem as boas práticas de projeto, implantação e operação de um DC, e são normalmente estabelecidas por associações técnicas industriais [29]. São estas normas que estabelecem os limiares de operação dos equipamentos, cabeamento estruturado, distribuição elétrica, refrigeração, etc. As normas podem ser as mesmas utilizadas no projeto de desenvolvimento do DC ou podem ser considerados os limiares, parâmetros e métricas indicadas nas políticas.

Quando é necessário conhecer o impacto da implementação de uma política, pode-se identificar o comportamento dos parâmetros através de métricas específicas. Para aferir a eficácia da aplicação de uma determinada política, deve-se comparar o valor da métrica antes e depois desta ação. Uma métrica pode ser utilizada a nível operacional, como um indicador de produção, ou a nível de negócios, como um indicador de desempenho. Existem diversas métricas que podem ser utilizadas em um DC segundo a pesquisa de [30], porém devem ser selecionadas conforme a política implementada, o parâmetro analisado e a atividade-fim do DC, destacando as que são aceitas e utilizadas pela indústria para prover uma comparação consistente. Em caso de indisponibilidade de uma métrica coerente com o objetivo da política implementada, podem ser usadas relações simplificadas entre a produtividade do equipamento, como largura de banda, frequência de CPU, Operações de Ponto Flutuante por Segundo (FLOPS) ou British Thermal Unit (BTU), e seu consumo de energia, como Watt-hora (Wh) ou Joules (J). Destas relações surgem novas métricas, como por exemplo FLOPS/Wh, BTU/J, etc.

A nível de negócios, uma análise adicional está relacionada a monitoração da variação do custo energético, um fator essencial para o apoio a decisão de manter ou modificar a política quando retornar para a etapa 3. Assim, deve-se considerar a métrica retorno sobre investimento (ROI) que de maneira abstrata é dada pela relação direta entre ganho e custo, e sua equação usada para termos de eficiência energética especificada na Seção 3.7. Isso permite dar uma previsão de tempo para que o investimento realizado possa retornar para a organização em forma de economia com energia elétrica.

\subsection{Descrição dos equipamentos}

Inicialmente, na etapa (c) da Fase Preparatória do método (Figura 2-I), o perfil energético dos equipamentos do DC já foi definido com a descrição do consumo e potência de todos equipamentos presentes no DC. Nesta segunda etapa da Fase de Aplicação, deve ser concentrada apenas as informações dos equipamentos correlatos a política que está sendo implementada. Indica-se o modelo de dados em tabela, relacionando os equipamentos em duas categorias: os computacionais e os de suporte. A catego-

\footnotetext{
${ }^{3}$ Disponível em: <http://datacenters.lbl.gov/tools/8-data-center-master-list-efficiency-actions>.

${ }^{4}$ Disponível em: <https://e3p.jrc.ec.europa.eu/communities/data-centres-code-conduct>.
} 
ria de equipamentos computacionais normalmente são relacionados com os tipos de servições providos pelo DC, como por exemplo: (i) comunicação/rede (switches, roteadores, hubs, etc); (ii) processamento (servidores); e (iii) armazenamento distribuído (NAS/SAN).

Os equipamentos de suporte são os responsáveis pelo funcionamento adequado dos equipamentos computacionais, por exemplo: (i) fontes dos servidores; (ii) unidade de distribuição de energia (PDU); (iii) fonte de energia ininterrupta (UPS); (iv) transformadores ou estabilizadores de energia; (v) sistema de refrigeração; (vi) iluminação; (vii) estações de trabalho da equipe de TI; entre outros.

Em cada categoria de equipamento, podem ser analisadas informações como: (i) potência dos equipamentos (potência e consumo médio, em Watt (W) ou Joules (J)); (ii) capacidade de cada equipamento, tais como FLOPS, frequência e número de núcleos dos processadores, vazão de rede, quantidade de portas dos switches; perda de energia na conversão, distribuição e armazenamento de energia; capacidade da refrigeração em (BTU); e iluminação efetiva. (iii) idade dos equipamentos (ano de fabricação/aquisição); (iv) percentual de carga média de utilização dos equipamentos. Fazer o refinamento da etapa (c) para a etapa (2), permite na etapa (3) que a definição da abordagem tenha maior profundidade, auxiliando também no relatório final.

\section{3 (Re)definição da abordagem}

A definição de um plano de ação para cada política auxilia na melhor compreensão e organização dos objetivos a serem alcançados. Recomenda-se adotar um framework de gestão de projeto e/ou planejamento estratégico que seja de domínio dos membros da equipe, que devem orientar o gestor a definir os objetivos intrínsecos a cada política. Um exemplo de framework é o 5W2H [31], onde são definidas as respostas para sete questões básicas: o quê?, por quê?, onde?, quem?, quando?, como? e quanto?. Estas respostas constituirão o escopo inicial para o planejamento estratégico, permitindo implementar as políticas de modo simplificado, aperfeiçoando-as durante o ciclo de refinamento. Nessa etapa, também são estabelecidas as metas a serem atingidas, como o percentual de eficiência energética estimado e um prazo final para alcançar este objetivo. A definição da metas devem ser possibilitar que sejam atingidas no tempo estipulado, permitindo a implementação das demais políticas. Ressalta-se que todas as demais etapas terão influência no planejamento realizado na presente etapa.

Após a etapa de decisão determinada na análise de dados (etapa 7), a presente etapa poderá ser verificada novamente enquanto o ciclo de refinamento da eficiência energética não for alcançado. Neste momento, a presente etapa poderá ser designada como 'redefinição da abordagem' e as questões que foram previamente definidas deverão ser revisadas com objetivo de alcançar a eficiência energética desejada. As demais etapas (4, 5, 6 e 7) poderão ou não sofrer alterações devido às revisões da etapa 3.

\subsection{Framework de monitoramento}

O monitoramento do consumo energético é uma parte fundamental para o PEE de uma organização, pois estas informações permitirão identificar os critérios para a melhoria da eficiência energética e se os objetivos estão sendo alcançados. A presente etapa consiste na definição da ferramenta de monitoramento, seja manualmente com ferramentas básicas ou automatizada por uma solução de monitoramento. Salienta-se que, ao optar por um monitoramento manual, exige-se um grau maior de dificuldade em manter o seu plano de testes consistente, devido a uma maior probabilidade de erros. O mais adequado para um ambiente de DC é adotar uma solução de monitoramento automatizada, que possibilite obter dados mais precisos em menos tempo.

Normalmente, esta é uma etapa que exige um investimento financeiro inicial, pois é necessário adquirir a solução de monitoramento, caso a organização não possua uma. É possível encontrar no mercado 
ferramentas que permitem mensurar os parâmetros relativos à política implementada. São exemplos de parâmetros os relacionados à qualidade da energia elétrica, como o fator de potência, tensão, corrente, (essenciais para mensurar o consumo de energia); e qualidade ambiental, como temperatura, umidade, pressão atmosférica, iluminação, poeira, movimento, entre outros. Especificamente sobre a verificação da eficiência energética, é de suma importância utilizar sensores de consumo de energia para mensurar o consumo dos equipamentos e conhecer o seu comportamento em diversas situações, como durante as alterações de demanda, em níveis de uso mínimo, normal e máximo.

Existem soluções completas e específicas para o gerenciamento da infraestrutura do DC (e.g., soluções Data Center Infrastructure Management (DCIM)) que oferecem informações operacionais do DC, como a carga atual de processamento, tráfego de rede, quantidade de máquinas em uso, entre outros. Como exemplo de ferramentas DCIM, destaca-se Emerson Network Power ${ }^{5}$, Schneider Electric ${ }^{6}$, Nlyte Software $^{7}$, Commscope ${ }^{8}$, Panduit ${ }^{9}$ e Fazion ${ }^{10}$. Porém, a grande maioria destas soluções são proprietárias e exigem um valor de investimento substancial, sendo comum que organizações de pequeno a médio porte não tenham uma solução de monitoramento em sua infraestrutura DC.

\subsection{Plano de testes}

Um plano de testes consistente deve permitir uma comparação fidedigna entre o cenário a priori e a posteriori à aplicação da política. Isto possibilita mensurar a eficiência energética obtida em cada ciclo de refinamento e acompanhar a evolução do PEE. Antes de aplicar as ações da política em curso, os equipamentos devem ser monitorados para conhecer o seu comportamento nas diversas condições de uso, constituindo um teste inicial para cada uma das políticas a serem implementadas.

Normalmente, a etapa de definição da abordagem (etapa 3) fornecerá informações para a definição do plano de testes, tais como as metas de eficiência, os locais a serem mensurados e os prazos definidos. Salienta-se que é natural haver inconsistências durante os primeiros testes, que serão eliminados a cada nova iteração do ciclo de refinamento. Deve-se também observar os comportamentos externos ao ambiente monitorado, como a variação da carga de trabalho dos equipamentos e as condições climáticas externas, por exemplo. Neste plano de testes, devem ser especificados os locais de monitoramento, seja no sistema manual ou automatizado. Os pontos de monitoramento devem estar dispostos de forma mais granular possível, pois quanto maior for a especificidade da área monitorada, maior a precisão na análise dos resultados.

\subsection{Implementação da política e coleta dos dados}

Nesta etapa ocorre a efetiva implementação da política, conforme a abordagem definida na etapa 3 e no plano de testes da etapa 5. O plano de testes deve ser rigorosamente aplicado, mas caso haja a necessidade de fazer qualquer modificação, esta deve ser documentada e os testes deverão ser refeitos com as novas alterações. Indica-se realizar uma medição de prova com instrumentos calibrados (como um multímetro, termômetro, barômetro, etc.), para averiguar a consistência das informações coletadas pelos sensores. Deve-se ter em vista que podem ocorrer falhas e interferências nestes dispositivos, bem como estarem mal posicionados, e.g., um sensor de temperatura posicionado incorretamente como prevê uma determinada norma.

\footnotetext{
${ }^{5}$ Trellis - <http://www.emersonnetworkpower.com>

${ }^{6}$ InfraStruXure - <http://www.schneider-electric.com $>$

${ }^{7}$ Nlyte - <http://www.nlyte.com>

8 iTracks CPIM - <http://www.itracs.com>

${ }^{9}$ SynapSense - <http://www.synapsense.com>

${ }^{10}$ DataFaz - <http://www.datafaz.com>
} 
Os dados coletados podem ser persistidos conforme a abordagem de monitoramento selecionada na etapa 4, devendo-se prezar pela organização destes dados para facilitar a fase de análise e estabelecimento de uma coleta consistente. Na coleta manual, todos os dados devem ser coletados diariamente nos mesmos horários e devem ser adicionados à uma planilha que forneça resumos, organizada por parâmetros, horários e locais mensurados. No caso da coleta automatizada, a solução de monitoramento deve persistir os dados em uma base de dados, além de fornecer gráficos resumidos em um painel de indicadores ao usuário em tempo de operação, a fim de facilitar uma análise parcial durante a fase de coleta de dados. A persistência destas informações deve ser mantida por tempo indeterminado, devido a possibilidade de serem anexados aos relatórios e consultados posteriormente.

\subsection{Análise dos resultados}

Esta etapa é constituída pela questão de decisão: “as variações dos dados ultrapassam os limiares previamente estabelecidos?" e assume duas possíveis respostas: Sim, se os dados estão fora dos limiares previamente estabelecidos na etapa 1; e Não se os dados estão em conformidade com estes limiares. No primeiro caso, se os dados coletados ultrapassam os limiares, então a eficiência atingida é inválida, pois o desempenho do conjunto de equipamentos pode estar comprometido. Neste caso há o efeito ricochete, em que a eficiência energética é ocasionada pela redução no desempenho do equipamento para além dos limiares estabelecidos [32]. Portanto, deve-se manter no ciclo de refinamento (ciclo 7.1) e retornar para a etapa de redefinição da abordagem. No segundo caso, quando a variação dos dados não ultrapassa os limiares, então a eficiência desejada foi atingida e deve-se manter no ciclo de monitoramento (ciclo 7.2). É importante verificar se todos os parâmetros estão em conformidade com o estabelecido nas normas encontradas na etapa 1. Nesta etapa, para calcular a eficiência energética obtida, pode ser aplicada a Equação 1, geralmente para mensurar a eficiência através da diferença entre o estado inicial e o atual. Esta equação, embora simples, é considerada como uma das bases do protocolo IPMVP.

$$
\text { Economia }_{p}=\left(\text { Consumo }_{\text {Inicial }}-\text { Consumo }_{\text {Atual }}\right) \pm \text { Ajustes }
$$

O Consumo $_{\text {Inicial }}$ é o valor de consumo de energia mensurado no início da implementação de uma determinada política $p$. Já o Consumo Atual é o valor observado após a implementação da política $p$, observado na presente etapa de análise dos dados. A Eq. 1 é definida pelo protocolo IPMVP para propósitos gerais [26], sendo a variável ajustes adicionada para abranger sua aplicabilidade. Assim, Ajustes pode ser usado para corrigir eventuais margens de erro observadas antes e depois das medições, e.g., picos de demandas ou mudanças climáticas incontroláveis, considerando a mesma unidade de medida dos consumos relacionados, podendo ser adicionado ou subtraído. Para permitir que a Economia $a_{p}$ obtida na Eq. 1 seja harmonizada com as demais implementações de outras políticas, seu valor pode ser também obtido em um percentual sobre o consumo inicial, conforme especificado na Equação 2.

$$
\text { Economia }_{p}(\%)=\left(\frac{\text { Consumo }_{\text {Inicial }}-\text { Consumo }_{\text {Atual }}}{\text { Consumo }_{\text {Inicial }}} \pm \text { Ajustes }\right) * 100 \%
$$

Assim, após atingir o ciclo 7.2, os equipamentos devem operar nas configurações encontradas como ideais, e se possível, manter o sistema de monitoramento para verificar se os dados coletados continuarão em conformidade, mesmo em demandas adversas. Adicionalmente, pode-se calcular a economia financeira gerada através da Equação 3, para especificar em quanto tempo o retorno financeiro dos investimentos realizados estão cobertos por esta economia. O Custo base refere-se ao custo com o conjunto de equipamentos relacionados com a política atualmente em execução, que deve ser verificado antes de 
implementar a política. Do mesmo modo que o Custo $_{\text {atual }}$, relativo ao custo calculado após a implementação da política atual. Por fim, a variável Investimentos refere-se à soma de todos os investimentos necessários para a implementação da política atual. O resultado da Equação 3 será um valor percentual que indicará em quanto tempo o retorno sobre o investimento realizado estará devidamente coberto, sendo o restante considerado como lucro.

$$
R O I=\frac{\text { Custo }_{\text {base }}-\text { Custo }_{\text {atual }}}{\text { Investimento }}
$$

Deve-se finalizar o relatório com as configurações encontradas e ações identificada que permitiram a obter a eficiência. Por fim, manter a prática da política atual continuamente em execução permitirá manter a eficiência encontrada, iniciando a Fase de Aplicação (II) com uma nova política, previamente listada na etapa (e) da Fase Preparatória.

\subsection{Considerações sobre o método proposto}

Em uma análise geral sobre o método proposto de harmonização para o consumo de energia em DC, observa-se que é composto por diversas etapas bem definidas, organizadas em duas fases, que são concebidas para que os próprios membros da organização possam implementar o seu PEE. Neste sentido, retomando as características definidas para os trabalhos correlatos na Tabela 1, devido ao fato de o MeHarCEn ser desenvolvido especificamente para DCs, o critério (i), possui um baixo grau de complexidade, pois as políticas implementadas são de domínio técnico da organização. Ainda, o custo financeiro restringe-se ao investimento das ferramentas de monitoramento e, em alguns casos, para aplicar políticas específicas. Portanto, o critério (ii) relativo ao custo financeiro necessário para implantar o método é satisfeito representando um baixo custo; O critério (iii) também é satisfeito, pois há uma sistemática para aplicação do MeHarCEn, que é concebida para obter a eficiência energética de modo contínuo e iterativo, quando comparado com as ferramentas do LBNL. Por fim, o critério (iv), que concerne na aplicação autossuficiente do método é satisfeito, pois como as etapas estão organizadas e descritas para este propósito, e não há exigência de conhecimento prévio do método para colocá-lo em prática; Para confirmar a satisfazibilidade destes critérios, o MeHarCEn é aplicado um estudo de caso em um ambiente real, com uma política de simples implementação mas de alto impacto energético.

\section{Estudo de caso}

Com o objetivo de aplicar o método proposto, na presente seção é descrito a aplicação prática de todas as etapas do MeHarCEn em um estudo de caso real. O ambiente de estudo de caso é o Laboratório de Processamento Paralelo e Distribuído (LabP2D) da UDESC, que consiste em um DC que oferece recursos para realização de atividades de pesquisa, ensino e extensão à comunidade acadêmica da UDESC. É escolhido o LabP2D devido a similaridade com organizações de pequeno a médio porte, que usualmente começam empregando desktops como servidores e depois expandem a sua capacidade com servidores de rack. Mesmo caracterizado como um laboratório de pesquisa, todos os sistemas computacionais e de suporte são mantidos em funcionamento contínuo, exceto a iluminação que é ligada apenas enquanto a sala está ocupada e as cinco estações de trabalho (com desktops e monitores LCD) que são utilizados apenas para o gerenciamento da nuvem computacional OpenStack. Salienta-se que durante a aplicação do método proposto, o laboratório manteve-se com o mesmo perfil de equipamentos e de utilização. 


\subsection{Fase preparatória do MeHarCEn}

Na fase preparatória, são definidos como responsáveis do Programa de Eficiência Energética (PEE) do LabP2D, os quatro autores do presente trabalho. Mesmo tratando-se de uma organização pública (Universidade Estadual de Santa Catarina), é necessário especificar um orçamento inicial para o projeto, conforme estabelecido na etapa (b) da Fase Preparatória (I). Assim, os coordenadores do laboratório dispunham de um investimento de $\mathrm{R} \$ 2.000,00$ para a implementação do PEE, destinado principalmente ao desenvolvimento de um sistema de monitoramento energético e de temperatura para a sala de servidores. A partir deste orçamento, são definidas as estratégias a serem tomadas e as definições das políticas que possam ser implementadas dentro do valor estipulado. Todos os equipamentos do ambiente estão descritos na Tabela 2.

Tabela 2. Descrição simplificada dos equipamentos do DC.

\begin{tabular}{|c|c|c|c|c|c|c|c|}
\hline Classe & Subsistemas & Equipamento & Fabricante & Quant. & Potência & Capacidade & Fabricação \\
\hline \multirow{3}{*}{$\begin{array}{c}\text { Compu- } \\
\text { tacional }\end{array}$} & \multirow{2}{*}{ Servidores } & Desktop & $\mathrm{HP}$ & 30 & $450 \mathrm{~W}$ & 4 núcleos+4GB RAM & 2008 \\
\hline & & Rack & Huawei & 4 & $2 \times 500 W$ & 24 núcleos+96GB RAM & 2012 \\
\hline & Rede & Switch & Cisco & 4 & $200 \mathrm{~W}$ & 48 portas Gigabit & 2012 \\
\hline \multirow{4}{*}{ Suporte } & Refrigeração & Ar cond. split & Electrolux & 1 & $2600 \mathrm{~W}$ & $30000 \mathrm{BTU}$ & 2010 \\
\hline & Iluminação & Fluorescente & Osram & 12 & $40 \mathrm{~W}$ & $480 \mathrm{~W}$ & - \\
\hline & \multirow{2}{*}{$\begin{array}{l}\text { Estações } \\
\text { de suporte }\end{array}$} & Desktops & HP & 5 & $450 \mathrm{~W}$ & 4 núcleos+4GB RAM & 2008 \\
\hline & & Monitores LCD & Samsung & 5 & $70 \mathrm{~W}$ & LCD 19" & 2009 \\
\hline \multicolumn{4}{|c|}{ Total } & 61 & $23830 \mathrm{~W}$ & \multicolumn{2}{|l|}{ - } \\
\hline
\end{tabular}

Realizado o estudo das políticas de eficiência descritas no "Master List of Energy Efficiency Actions", desenvolvidas pelo LBNL, são selecionadas as políticas que possuem relação com o conjunto de equipamentos pertencentes ao LabP2D. Esta lista foi priorizada pela maior capacidade de obter a eficiência energética e pela menor complexidade de implementação. Ao realizar uma análise prévia do perfil energético do DC, observa-se que há dois pontos críticos de consumo de energia: os servidores e o sistema de refrigeração. Para obter alguma redução de consumo de energia nos servidores, é exigida a renovação por equipamentos energeticamente mais eficientes, porém foi decidido como algo indesejável no momento devido ao orçamento disponível. Por sua vez, o sistema de refrigeração apresenta uma série de características que indicam problemas operacionais, como o o fate de o equipamento não ser de precisão, a recirculação de ar quente e a sua operação constante na temperatura mínima de $18^{\circ} \mathrm{C}$. Deste modo, foi selecionado como a primeira política de eficiência energética a ser implementada, as ações relacionadas ao equipamento de refrigeração da sala de servidores do LabP2D. Para a aplicação das sete etapas do MeHarCEn, a política selecionada é a EC-002 da LBNL, que consiste em aumentar a temperatura do ar condicionado para os limiares recomendados por alguma norma de referência.

\subsection{Políticas de eficiência energética}

Especificamente para a política selecionada (EC-002), foram verificadas as normas técnicas: American Society of Heating, Refrigerating and Air-Conditioning Engineers (ASHRAE)-TC 9.9, ISO/IEC 24764, European Committee for Electrotechnical Standardization (CENELEC)-50600-x, ANSI/Building Industry Consulting Service International (BICSI)-002 e a ANSI/Telecommunications Industry Association (TIA)-942-A [33, 34, 35, 36, 37]. Ao consultar as condições ambientais especificadas nas políticas, 
indica-se que a temperatura de operação seja mantida no limite superior das recomendações da ASHRAETC 9.9, que é $27^{\circ} \mathrm{C}$. Todavia, os servidores possuem uma idade relativa de nove anos e a ASHRAE [33] indica que informações mais precisas podem ser encontradas em outras normas, desenvolvidas conforme o ano de fabricação dos equipamentos. Ao pesquisar nas demais normas, é encontrada a TIA-942-A de 2005 [37], na seção das considerações ambientais, estabelece uma faixa de operação ambiental menor que a indicada pela ASHRAE, conforme relacionada na Tabela 3.

Tabela 3. Requisitos do sistema de refrigeração de DC. Adaptado de [37] e [33].

\begin{tabular}{|c|c|c|c|c|}
\hline \multirow{2}{*}{ Requisitos } & \multicolumn{2}{|c|}{ Valores } & \multirow{2}{*}{ Normal } & \multirow{2}{*}{ Unidades } \\
\cline { 2 - 3 } & Mínimo & Máximo & & \\
\hline \hline Temperatura Bulbo Seco (TBS) & 20 & 25 & 22 & ${ }^{\circ} \mathrm{C}$ \\
\hline Variação máxima da TBS & 0 & 5 & - & ${ }^{\circ} \mathrm{C} /$ hora \\
\hline Ponto de orvalho máximo & 0 & 21 & - & ${ }^{\circ} \mathrm{C}$ \\
\hline Umidade relativa & 40 & 55 & 45 & $\%$ \\
\hline
\end{tabular}

$\mathrm{Na}$ Tabela 3 estão especificadas as faixas de temperatura, umidade relativa, ponto de orvalho e a variação máxima da temperatura por hora, considerados como parâmetros a serem analisados. Quando há equipamentos heterogêneos, como no presente cenário, indica-se a utilização da faixa de condições ambientais mais restritiva, para assegurar a longevidade dos componentes eletroeletrônicos. Assim, serão mantidos os limiares definidos pela norma TIA-942-A como as faixas de valores de mínimo e máximo, i.e., temperatura entre 20 e no máximo $25^{\circ} \mathrm{C}$, variando até $5^{\circ} \mathrm{C} /$ hora, e umidade entre $40 \%$ e $55 \%$.

As métricas utilizadas para quantificar a efetividade da política adotada são o Power Usage Effectiveness (PUE) e o Data Center Infrastructure Efficiency (DCiE). Elas mostram a eficácia dos sistemas de suporte em relação aos sistemas computacionais, neste caso, a capacidade em que o DC é resfriado e fornece energia para os servidores [2]. O PUE pode ser considerado como uma métrica de eficácia, uma vez que o desempenho dos servidores não está incluído no cálculo. As métricas estão descritas nas Equações 4 e 5.

$$
P U E=\frac{P_{\text {total }}}{P_{T I}} \quad \text { (4) } \quad \text { DCiE }=\frac{1}{P U E} * 100 \%
$$

Na Equação 4, a variável $P_{\text {total }}$ é a potência total de acesso, i.e., toda a energia elétrica consumida pelo DC, enquanto a variável $P_{T I}$ é a potência consumida exclusivamente pelos equipamentos de TI. Os valores do PUE variam de 1 ao infinito, sendo que quanto mais próximo de 1 , mais eficiente é o DC. $\mathrm{Na}$ Equação 5, a métrica DCiE é o inverso do PUE para uma taxa que varia de $0 \%$ a $100 \%$, e quanto maior este valor, mais eficiente é o DC. Deste modo, para calcular estas métricas é necessário obter os parâmetros de consumo de energia de todos os equipamentos, mas separando-os em equipamentos de TI e de suporte.

\subsection{Descrição dos equipamentos}

Em uma área total de trinta metros quadrados, o LabP2D abriga os equipamentos listados na Tabela 2. Embora a presente política de eficiência esteja focada apenas no sistema de refrigeração, as métricas PUE/DCiE exigem o cálculo do consumo de energia total. Por este motivo, todos os equipamentos presentes na Tabela 2 fazem parte da descrição dos equipamentos relacionados pela política atual.

Os computadores desktop estão organizados em corredores quente e frio, onde há a recirculação do ar quente devido a natureza da origem do insuflamento, um equipamento de refrigeração split. O uso desse tipo de equipamento de refrigeração não é convencional em ambientes de DCs de grande porte. Como 
os gestores do DC desconheciam a demanda de temperatura gerada pelo conjunto de equipamentos, o equipamento de refrigeração estava configurado constantemente na temperatura de $18^{\circ} \mathrm{C}$, i.e., na potência máxima de refrigeração.

\section{4 (Re)definição da abordagem}

Nesta etapa define-se um plano de ação, recomendado que seja adotado algum que seja de conhecimento dos membros da equipe. Como os autores já utilizam o framework What, Why, Where, Who, When, How e How much (5W2H), então adota-se este como padrão. As sete questões do plano de ação $5 \mathrm{~W} 2 \mathrm{H}$ são respondidas de forma sucinta a a priori, e estendidas ou alteradas conforme as necessidades encontradas a posteriori. Salienta-se que esta é uma etapa que ao ser revisitada no ciclo de refinamento, as respostas são aprimoradas no decorrer dos ciclos. Todas estas respostas podem ser utilizadas em etapas futuras do método MeHarCEn.

- $O$ quê? Aumentar a temperatura do ar condicionado, garantir que não ultrapasse os limites superiores estabelecidos para temperatura e umidade.

- Por quê? Basear-se corretamente na norma TIA-942-A e reduzir o consumo de energia conforme a lista de eficiências.

- Quanto? Estima-se investir apenas em uma solução de monitoramento energético e ambiental.

- Quem? Os responsáveis pelo DC aplicarão as regras para os demais utilizadores do DC. Serão colocados avisos próximo ao equipamento de refrigeração.

- Onde? No sistema de refrigeração, dentro da sala de servidores.

- Quando? Sete dias para realizar cada um dos três testes: temperatura atual em $18^{\circ} \mathrm{C}$, temperatura no valor médio $23^{\circ} \mathrm{C}$ e temperatura superior a $25^{\circ} \mathrm{C}$. Vinte e um dias para a finalização total.

- Como? Serão instalados sensores em pontos estratégicos para medir os parâmetros ambientais (corredores quentes e frios), sensores de consumo de energia no sistema de refrigeração e nos demais equipamentos para calcular a métrica PUE.

\subsection{Framework de monitoramento}

Para avaliar o impacto da eficiência energética obtida, é necessário mensurar o consumo de energia elétrica dos equipamentos relacionados, bem como os parâmetros ambientais para verificar se estão em conformidade com o estabelecido nas normas. Como estes parâmetros devem ser preferencialmente obtidos de forma automática, sem a intervenção do operador, é utilizada a solução GreenHop ${ }^{11}$ que faz o monitoramento ambiental e energético da sala de servidores e é especificamente desenvolvida para DCs. Uma das características da solução GreenHop é ser independente da infraestrutura existente (computacional e rede), pois é utilizada uma Rede de Sensores Sem Fio (RSSF) e não necessita modificar a infraestrutura existente para a realização dos testes.

O GreenHop é uma solução open source e foi desenvolvida pelos autores do presente trabalho com o objetivo de ser uma ferramenta flexível e de baixo custo de investimento. Foram pesquisadas diversas soluções de monitoramento para ambientes de DC, mas a sua grande maioria são proprietárias e exigem um alto valor de investimento. Para ser aplicado no MeHarCEn, o desenvolvimento do GreenHop exigiu um investimento de R\$1.700,00, pois mesmo tratando-se de uma solução open source, é necessário a aquisição de componentes de hardware, tais como microcontroladores, sensores e o single board computer Banana Pi. A versatilidade da solução GreenHop permite aplicá-la em diversos outros PEEs, apenas

\footnotetext{
${ }^{11}$ Disponível em: <https://sourceforge.net/projects/greenhop>
} 
alterando os sensores conforme a necessidade. Todavia, isso não implica que uma organização deva utilizar ou desenvolver sua própria versão de GreenHop para aplicar o MeHarCEn em sua infraestrutura.

Após identificar os pontos estratégicos para monitoração do DC, os nodos do framework de monitoração foram distribuídos, conforme indica a Figura 3. O nodo coordenador $\left(N_{1}\right)$ está localizado na mesa da equipe de suporte e conectado ao Banana Pi. Dentre os nodos finais, destacam-se os nodos $N_{2}$ e $N_{7}$, que além de monitorar os parâmetros ambientais ainda monitoram o consumo de energia. De forma mais precisa, o nodo $N_{2}$ mensura o consumo de energia dos sistemas computacionais através de três sensores, sendo um sensor posicionado no PDU de cada uma das duas fileiras dos computadores desktop e um sensor no rack. O nodo $N_{7}$ está posicionado no quadro de energia, e mensura o consumo dos sistemas de suporte com dois sensores, sendo um sensor para a iluminação e bancada operacional e outro sensor apenas para o ar condicionado. Portanto, o consumo de energia é feito através de cinco sensores de corrente elétrica do tipo não-invasivo (SCT013-000), alocados em apenas dois nodos finais, sendo que o $N_{2}$ mensura o consumo dos sistemas computacionais e o $N_{7}$ mensura o consumo dos sistemas de suporte.

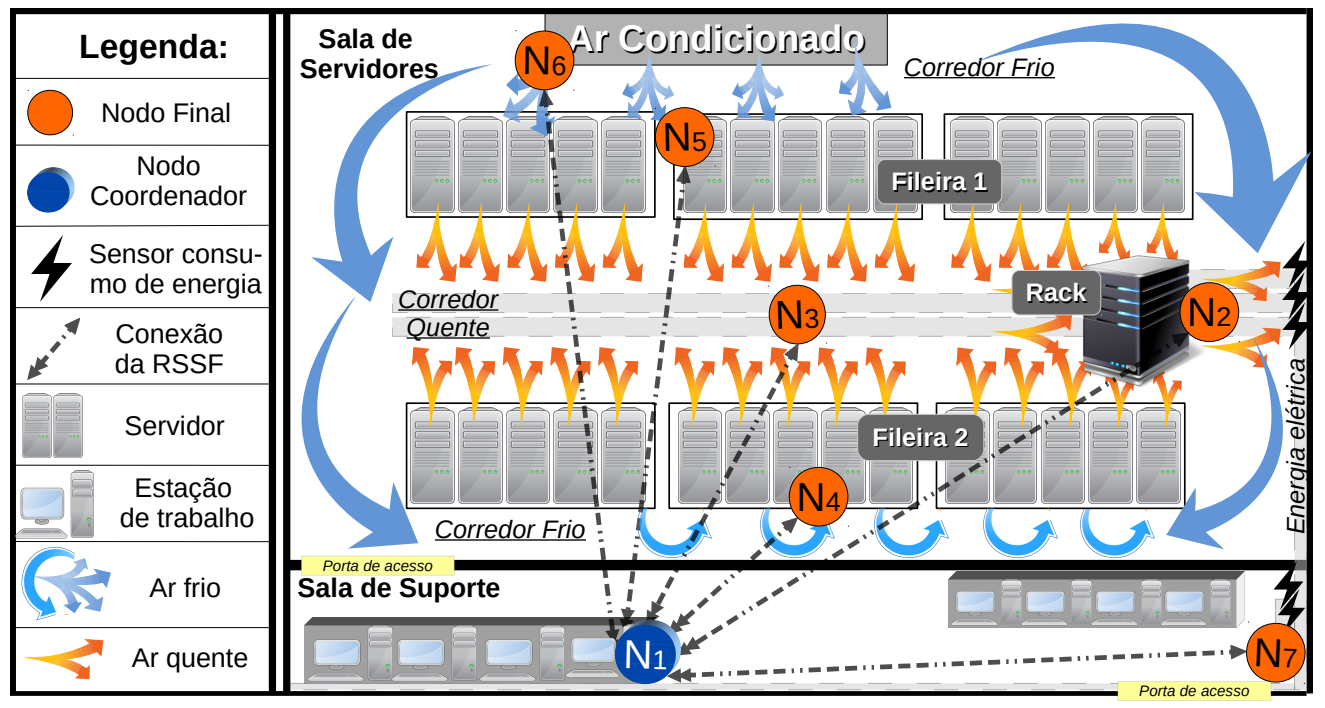

Figura 3. Distribuição dos nodos do framework de monitoramento no LabP2D.

Os demais nodos $N_{3}, N_{4}, N_{5}$ e $N_{6}$, monitoram apenas os parâmetros ambientais e estão distribuídos entre corredores quentes e frios. O nodo $N_{2}$ está posicionado na saída de ar quente do rack, o $N_{3}$ no meio do corredor quente formado pelos computadores desktops, dois nodos, $N_{4}$ e $N_{5}$, posicionados nos corredores frios, o $N_{6}$ na saída do ar condicionado e por fim, o $N_{7}$ posicionado no quadro de energia, externo à sala de servidores, mas ainda dentro do laboratório. O ideal é ter a maior quantidade possível de pontos de coleta, pois quanto maior for a quantidade de informações, maior será o detalhamento dos resultados. Todos os nodos finais, com exceção do $N_{6}$ posicionado na saída de ar do equipamento de refrigeração, estão a uma altura de 1,5 metros do piso. Como o presente PEE demanda uma maior quantidade e variedade de dados, pode-se classificá-lo com a opção $C$ do protocolo IPMVP. Sua principal característica é a necessidade de mensurar diversos parâmetros-chave, distribuídos em praticamente toda a infraestrutura dos sistemas de suporte e computacional. 


\subsection{Plano de testes}

As especificações da norma TIA-942-A são utilizadas como referência, sendo que as características ambientais do laboratório devem ser mantidas entre as faixas de valores mínimo e máximo, conforme definidas na Tabela 3. Durante o período de testes, todos os equipamentos de computação estão com uma carga de processamento entre $30 \%$ e $60 \%$, alterando-se conforme a demanda inerente das diversas aplicações em execução. Apenas foi modificada a temperatura do equipamento de refrigeração de acordo com o plano de testes.

Tabela 4. Síntese do plano de testes realizado no LabP2D.

\begin{tabular}{|c|c|c|c|}
\hline Plano de Testes & Teste 1 & Teste 2 & Teste 3 \\
\hline \hline Temperatura interna & $18^{\circ} \mathrm{C}$ & $23^{\circ} \mathrm{C}$ & $25^{\circ} \mathrm{C}$ \\
\hline Incremento na temperatura & Base & $+5^{\circ} \mathrm{C}$ & $+7^{\circ} \mathrm{C}$ \\
\hline Temperatura externa & $22^{\circ} \mathrm{C}$ & $24^{\circ} \mathrm{C}$ & $25^{\circ} \mathrm{C}$ \\
\hline Duração dos Testes & 7 dias & 7 dias & 7 dias \\
\hline Período entre medições & 3 segundos & 3 segundos & 3 segundos \\
\hline
\end{tabular}

Com o objetivo de organizar e sintetizar o plano de testes, a Tabela 4 consolida as principais características dos três testes realizados. As características relacionadas são: a configuração da temperatura de funcionamento ar condicionado deve estar configurada, o incremento na temperatura base de $18^{\circ} \mathrm{C}$ para a nova temperatura interna e a temperatura média externa do local dos testes. O número de sensores e suas localizações serão as mesmas em todos os experimentos realizados. O período de observação desses experimentos deve ser de sete dias para cada teste, sendo as medições realizadas a cada três segundos e armazenadas em uma base de dados gerenciada pelo próprio Zabbix. Durante todos os testes devem ser utilizados a mesma organização dos nodos, devendo-se realizar a verificação do consumo de energia nos sistemas computacionais e de suporte separadamente para permitir utilizar a métrica PUE.

\subsection{Implementação da política e coleta dos dados}

A implementação da política consiste na própria aplicação do plano de testes. Devido ao uso de uma solução com as características do GreenHop, os resultados são analisados em tempo de operação (a cada três segundos) através dos diversos gráficos fornecidos pelo Zabbix em sua interface com o usuário. Estes gráficos sintetizam os valores de mínimo, médio, máximo e o último valor lido, para cada parâmetro analisado, compreendido em um período de tempo selecionado. Durante os testes, foram detectadas oscilações anormais no consumo de energia que estão associadas aos momentos em que o compressor do equipamento de refrigeração é ligado e desligado. Esse comportamento leva aos gráficos possuírem oscilações similares a ondas quadradas, que só foram possíveis detectar devido ao monitoramento contínuo com intervalos de tempo de três segundos e que seriam mascarados em uma média diária ou em medições com intervalos de tempos maiores. Durante os testes, os picos de consumo no instante inicial em que o compressor é ligado ultrapassam de $5 \mathrm{kWh}$, que impacta instantaneamente na demanda de potência, que por consequência impacta na métrica PUE.

\subsection{Análise dos resultados}

Devido ao plano de testes estar consolidado e representar a expectativa dos operadores, houve a necessidade de revisar apenas quatro vezes todo o PEE para realizar ajustes. De forma unânime, todos os resultados permitiram identificar que não há necessidade de configurar o sistema de refrigeração em $18^{\circ} \mathrm{C}$ para manter o ambiente adequado para as operações de um DC. Manter a refrigeração dentro da faixa de $20^{\circ} \mathrm{C}$ a $25^{\circ} \mathrm{C}$, especificado na norma TIA-942-A (Tabela 3), é suficiente para manter a sala de 
servidores do LabP2D suficientemente refrigerada. A Tabela 5 apresenta os resultados consolidados dos experimentos realizados.

Tabela 5. Resultados dos experimentos dos parâmetros ambientais.

\begin{tabular}{|c|c|c|c|c|}
\hline \multirow{2}{*}{ Requisitos } & TIA-942-A & Teste 1 & Teste 2 & Teste 3 \\
& Min $\sim$ Max & $\mathbf{1 8}^{\circ} \mathbf{C}$ & $\mathbf{2 3}^{\circ} \mathbf{C}$ & $\mathbf{2 5}^{\circ} \mathbf{C}$ \\
\hline \hline TBS & $20 \sim 25^{\circ} \mathrm{C}$ & $18^{\circ} \mathrm{C}$ & $23^{\circ} \mathrm{C}$ & $25^{\circ} \mathrm{C}$ \\
\hline Variação TBS/h & $0 \sim 5^{\circ} \mathrm{C} / \mathrm{h}$ & $1,5^{\circ} \mathrm{C} / \mathrm{h}$ & $2^{\circ} \mathrm{C} / \mathrm{h}$ & $1,2^{\circ} \mathrm{C} / \mathrm{h}$ \\
\hline Ponto Orvalho & $0 \sim 21^{\circ} \mathrm{C}$ & $7^{\circ} \mathrm{C}$ & $16^{\circ} \mathrm{C}$ & $17^{\circ} \mathrm{C}$ \\
\hline Umidade & $40 \sim 55 \%$ & $39 \%$ & $52 \%$ & $60 \%$ \\
\hline Consumo do equipamento/dia & - & $27,1 \mathrm{kWh}$ & $12,5 \mathrm{kWh}$ & $5,64 \mathrm{kWh}$ \\
\hline Custo financeiro ao mês & - & $\mathrm{R} \$ 414,63$ & $\mathrm{R} \$ 191,25$ & $\mathrm{R} \$ 86,29$ \\
\hline ROI & - & Base & $13,14 \%$ & $19,3 \%$ \\
\hline Economia $($ Equação 2$)$ & - & Base & $52,7 \%$ & $79,2 \%$ \\
\hline PUE & - & 2,34 & 1,71 & 1,61 \\
\hline DCiE & - & $42,73 \%$ & $58,47 \%$ & $62,11 \%$ \\
\hline
\end{tabular}

Ao analisar os resultados descritos na Tabela 5, observa-se no Teste 3 que manter a temperatura em $25^{\circ} \mathrm{C}$ permite obter uma ótima eficiência energética. Todavia, esta opção de temperatura extrapola os limites superiores de umidade relativa, principalmente no período noturno. No Teste 2, selecionar uma temperatura intermediária $\left(23^{\circ} \mathrm{C}\right)$ mostra um consumo menor que o observado a $18^{\circ} \mathrm{C}$ e pouco maior que o consumo em $25^{\circ} \mathrm{C}$. Em geral, observa-se que quanto maior a temperatura, menor será o consumo ao dia, mas que os demais parâmetros devem ser analisados para a tomada de decisão sobre a configuração mais adequada. Assim, a configuração da temperatura em $23^{\circ} \mathrm{C}$ mostrou-se ideal por manter o ponto de orvalho e a umidade relativa como estabelecidos pela norma TIA-942-A, com um consumo aceitável de energia elétrica.

Adicionalmente, a análise sobre o ROI é dado pela equação $R O I=C / R \$ 1700,00$, em que $C=$ consumo dia $* 30 * R \$ 0,51$, observando, neste caso uma tarifa de $\mathrm{R} \$ 0,51 / \mathrm{kWh}$ de consumo de energia, um valor de referência consistente com os meses dos testes. Esta análise é importante para manter o apoio da direção em dar continuidade no PEE e manter os investimentos em implementações de novas políticas. Desse modo, a configuração da temperatura em $23^{\circ} \mathrm{C}$, indica um ROI de $13,14 \%$, que prática significa que em menos de oito meses a economia de energia com o ar condicionado já cobre o custo do sistema de monitoramento. Ainda que não seja possível mensurar diretamente os benefícios de manter a umidade dentro das faixas estabelecidas pela norma adotada, pois eleva-se o tempo de vida útil dos equipamentos de TI, bem como a vida útil do compressor do equipamento de refrigeração.

\subsection{Considerações gerais sobre os resultados coletados no estudo de caso}

Ao considerar as avaliações do monitoramento ambiental e do PUE, é possível concluir que a temperatura de operação mais adequada é a de $23^{\circ} \mathrm{C}$, pois mantém o parâmetros de umidade dentro dos requisitos estabelecidos pela norma TIA-942-A. Embora esta configuração não represente o menor consumo energético, aplicar o MeHarCEn permite obter a redução de 52,7\% (usando a Equação 2), simplesmente com a adequação da refrigeração para que garanta as condições mínimas ambientais, o que pode ser considerado um grande benefício. Nesta configuração o PUE se mantém em 1,71 pontos e o DCiE se mantém em $58,47 \%$. Adicionalmente foi constatado que o equipamento de refrigeração está corretamente dimensionado para a demanda térmica dos equipamentos na sala, pois possui um mecanismo eficiente para manter a temperatura ajustada conforme especificado. De acordo com os dados analisados, não houve variações de temperatura fora das faixas configuradas. 


\subsection{Considerações gerais sobre a aplicação de MeHarCEn}

A aplicação do MeHarCEn no cenário analisado atendeu as expectativas, principalmente quanto a sua simplicidade de implementação e independência de sistemas proprietários de monitoração. O MeHarCEn forneceu o embasamento necessário para facilitar a tomada de decisões gerenciais. Sobretudo, não ofereceu nenhum impedimento para a aplicação das políticas, abordagens e equipamentos previamente utilizados no ambiente.

A transição da Fase Preparatória para a Fase de Aplicação foi facilitada pelo conhecimento e documentação prévia sobre os equipamentos existentes. Um caminho que requer atenção futura é a definição de novos planos de testes que, interconectados com a ferramenta de monitoração, possam fornecer uma nova percepção sobre o consumo energético. O fluxo de ar interno e a dissipação de calor dos equipamentos de processamento podem ser exemplos de novas adequações no ambiente. A própria atual Seção 4 pode ser considerada como um exemplo de relatório para exposição do modus operandi deste PEE com seus respectivos resultados.

\section{Considerações finais e trabalhos futuros}

O Método de Harmonização do Consumo de Energia para Data Centers - MeHarCEn - tem a sua aplicação bem sucedida no LabP2D, tendo em vista a redução dos custos com energia elétrica na aplicação de apenas uma política. Considerada de simples complexidade, elevar a temperatura do equipamento de refrigeração para $23^{\circ} \mathrm{C}$ possibilitou uma redução de $52,7 \%$ no consumo de energia deste equipamento, e ocasionou em uma redução do PUE para 1,71. Desse modo, as condições ambientais foram mantidas dentro dos limiares indicados pela norma TIA-942-A, evitando que a baixa umidade proporcionada pela condição de $18^{\circ} \mathrm{C}$ resultasse na eletricidade estática, indesejada em ambientes de DC. O investimento realizado para o sistema de monitoramento GreenHop tem seu retorno em menos de oito meses, sendo que depois disso, toda a economia é considerada como um lucro da implementação do MeHarCEn.

Todas as etapas do método MeHarCEn são importantes para a obtenção da eficiência energética, pois não obstante a política de eficiência seja a base da redução do consumo de energia, a organização e o planejamento permitem obter dados consistentes e comparáveis com a implementação de novas políticas. Contudo, o conjunto de etapas são especialmente úteis para o desenvolvimento de relatórios, sendo este relatório indicado para as finalidades de pesquisa e replicação das ações bem sucedidas para as demais organizações interessadas. Deste modo, como trabalhos futuros está previsto o desenvolvimento de uma solução Web que possibilite concentrar todas as informações de um PEE, integrando toda a documentação do MeHarCEncom exemplos de implementação prática, além de permitir contato com os pesquisadores que desenvolveram o método. Em contrapartida, os dados fornecidos poderão ser utilizados para a finalidade de pesquisa, permitindo a continuidade do desenvolvimento e evolução do método MeHarCEn.

Da mesma forma que a solução de monitoramento GreenHop, o método MeHarCEn é uma solução open source e disponibilizada sob a licença Apache V2.0. O objetivo de manter o MeHarCEn como uma solução aberta, é permitir aos gestores diminuírem o impacto ambiental do consumo de energia dos sistemas computacionais e de suporte. Assim, há a possibilidade de execução, estudo, modificação e replicação do método MeHarCEn, estimulando que as boas práticas de redução do consumo de energia seja uma preocupação constante no cotidiano de gestores de DC. 


\section{Agradecimentos}

Os autores agradecem a Fundação de Amparo à Pesquisa e Inovação do Estado de Santa Catarina (FAPESC) pelo apoio ao LabP2D da CCT/UDESC, e aos membros do LabP2D pela colaboração na aplicação do MeHarCEn.

\section{Contribuição dos Autores}

- Daniel Scheidemantel Camargo: Pesquisa e escrita do artigo;

- Maurício Aronne Pillon: Coordenação do trabalho e direcionamento de pesquisa;

- Charles Christian Miers: Direcionamento de pesquisa e correções de conceitos; e

- Guilherme Piêgas Koslovski: Direcionamento de pesquisa e correções de conceitos.

Adicionalmente, todos os autores contribuíram para o desenvolvimento dos testes, pois formaram a equipe de implementação da política aplicada no estudo de caso.

\section{Referências}

[1] SILVA, F. C. Data Centers (CPD) para pequenas e médias empresas. São Paulo, Brazil: Redes\&Cia, 2015. 39 p.

[2] PEGUS II, P. et al. Analyzing the efficiency of a green university data center. In: 7th ACM/SPEC. New York, USA: ACM, 2016. (ICPE '16). ISBN 978-1-4503-4080-9.

[3] VILLARS, R. L.; SHIRER, M. IDC Finds Growth, Consolidation, and Changing Ownership Patterns in Worldwide Datacenter Forecast. 2014. Disponível em: <www.idc.com>. Acesso em: 2016-03-08.

[4] EMERSON-ENERGY. Energy Logic 2.0 New Strategies for Cutting Data Center Energy Costs and Boosting Capacity. Columbus, Ohio, USA, 2012. 39 p.

[5] DAVID, M.; SCHMIDT, R. Impact of ASHRAE environmental classes on data centers. In: 2014 IEEE ITherm. Orlando, FL, USA: 2014 IEEE ITherm, 2014. p. 1092-1099.

[6] DELFORGE, P. America's Data Centers Consuming and Wasting Growing Amounts of Energy. New York, NY - USA, 2014. Disponível em: <http://www.nrdc.org/energy/data-center-efficiency-assessment. asp $>$.

[7] HOOGENDOORN, B.; GUERRA, D.; ZWAN, P. V. D. What drives environmental practices of SMEs? Springer Journall Small Business Economics, v. 44, n. 4, p. 759-781, nov 2014. ISSN 0921-898X, 1573-0913.

[8] MITTAL, S. Power Management Techniques for Data Centers: A Survey. CoRR, abr. 2014. ArXiv: 1404.6681 .

[9] MORABITO, R. Power Consumption of Virtualization Technologies: an Empirical Investigation. IEEE/ACM UCC 2015 SD3C, IEEE, 2015. Disponível em: <http://arxiv.org/abs/1511.01232>. 
[10] ISO-50001. Energy Management Systems - Requirements with guidance for use. Geneva, Switzerland, 2011. Disponível em: <http://www.iso.org/iso/home/standards/management-standards/ iso50001.htm>.

[11] COMERFORD, T. How Data Center Operators Can Avoid Energy Price Hikes This Winter. West Chester, OH, USA, 2015. Disponível em: <http://www.datacenterknowledge.com/archives/2015/01/29/ data-center-operators-can-avoid-energy-price-hikes-winter/>.

[12] STANSBERRY, M. Uptime Institute - Data Center Industry Survey 2013. Seattle, WA, USA, 2013. Disponível em: <https://uptimeinstitute.com/resources/asset/2013-data-center-industry-survey>.

[13] DELFORGE, P.; WHITNEY, J. Data Center Efficiency Assessment, scaling up energy efficiency across the Data Center Industry: evaluating Key Drivers and Barriers. USA, 2014. Disponível em: $<$ https://www.nrdc.org/sites/default/files/data-center-efficiency-assessment-IP.pdf>.

[14] NEWCOMBE, L. et al. 2016 Best Practice Guidelines for the EU Code of Conduct on Data Centre Energy Efficiency. European Union, EU, 2016. 50 p. Disponível em: <http: //iet.jrc.ec.europa.eu/energyefficiency/ict-codes-conduct/data-centres-energy-efficiency>.

[15] LBNL/US-DoE. Data Center Master List of Energy Efficiency Actions. Lawrence Berkeley National Laboratory - LBNL, 2016. 48 p.

[16] BIANZINO, A. P.; RAJU, A. K.; ROSSI, D. Apples-to-apples: A Framework Analysis for Energy-efficiency in Networks. SIGMETRICS Perform. Eval. Rev., v. 38, n. 3, p. 81-85, jan. 2011. ISSN 0163-5999.

[17] SAMARAKOON, S.; RAJINI, P. Enablers and barriers of implementing ISO 50001- energy management systems (EnMS) in sri lankan context. In: Socio-Economic Sustainability in Construction: Practice, Policy and Research. Colombo, Sri Lanka: CIB-SB13, 2013. v. 2, p. 208-217.

[18] FIEDLER, T.; MIRCEA, P. M. Energy management systems according to the ISO 50001 standard: Challenges and benefits. In: 2012 ICATE. Craiova, Romania: IEEE, 2012. p. 1-4.

[19] Bureau Veritas. Bureau Veritas Certification. Rio de Janeiro, RJ, Brazil: BVC, 2017. Disponível em: <http://www.bureauveritascertification.com.br/>.

[20] THERKELSEN, P. et al. Assessing the costs and benefits of the superior energy performance program. In: ACEEE-2013. Washington, DC - USA: National Press Building, 2013.

[21] KARAPETROVIC, S. Strategies for the integration of management systems and standards. The TQM Magazine, v. 14, n. 1, p. 61-67, fev. 2002. ISSN 0954-478X. Disponível em: <http://www.emeraldinsight.com/doi/abs/10.1108/09544780210414254>.

[22] WULANDARI, M. et al. IMPACT OF ISO 50001 STANDARD An empirical study. $1^{\mathrm{a}}$ ed., $1^{\mathrm{a}} \mathrm{imp}$. edition. ed. Girona: Documenta Universitaria, 2014. ISBN 978-84-9984-285-1.

[23] WULANDARI, M. et al. Early Adoption of ISO 50001 Standard: An Empirical Study. In: Sustainable Operations Management. Springer, Cham, 2015, (Measuring Operations Performance). p. 183-202. ISBN 978-3-319-14001-8 978-3-319-14002-5. DOI: 10.1007/978-3-319-14002-5_9. Disponível em: <https://link.springer.com/chapter/10.1007/978-3-319-14002-5\9>.

[24] ITURBE, I. L. Adopción de estándares de gestión energética e integración con estándares de gestión medioambiental. Tese (Ph.D. Thesis) - Universitat de Girona, maio 2015. Disponível em: $<$ http://www.tdx.cat/handle/10803/300901>. 
[25] MARCONI, M. d. A.; LAKATOS, E. M. Fundamentos de Metodologia Científica. Edição: 8a. São Paulo - Brasil: Atlas, 2017. ISBN 978-85-970101-2-1.

[26] EVO-WORLD, O. International Performance Measurement and Verification Protocol: Concepts and Options for Determining Energy and Water Savings. U.S. Department of Energy-USA, EVO World, 2002. Disponível em: <https://eric.ed.gov/?id=ED144007>.

[27] PETRI, I. et al. A modular optimisation model for reducing energy consumption in large scale building facilities. Renewable and Sustainable Energy Reviews, v. 38, p. 990-1002, out. 2014. ISSN 1364-0321. Disponível em: <http://www.sciencedirect.com/science/article/pii/S1364032114004961>.

[28] ALMiHOUB, A. A. A.; MULA, J. M.; RAHMAN, M. M. Marginal Abatement Cost Curves (MACCs): Important Approaches to Obtain (Firm and Sector) Greenhouse Gases (GHGs) Reduction. International Journal of Economics and Finance, v. 5, n. 5, abr. 2013. ISSN 1916-9728, 1916-971X. Disponível em: <http://www.ccsenet.org/journal/index.php/ijef/article/view/26701>.

[29] DAI, J. et al. Data center energy flow and efficiency. In: Optimum Cooling of DCs. NY-USA: Springer, 2014. p. 9-30. ISBN 978-1-4614-5601-8, 978-1-4614-5602-5.

[30] WANG, X. et al. A survey of green mobile networks: Opportunities and challenges. MNA, p. 4-20, feb 2012. ISSN 1383-469X, 1572-8153.

[31] KLOCK, A.; GASPARINI, I.; PIMENTA, M. 5w2h framework: A guide to design, develop and evaluate the user-centered gamification. In: . São Paulo-BR: IHC, 2016. Part F128046.

[32] HERRING, H.; SORRELL, S. Energy Efficiency and Sustainable Consumption: The Rebound Effect. United Kingdom, UK: Palgrave Macmillan, 2008. ISBN 978-0-230-52534-4.

[33] ASHRAE-STD 90.4. Energy Standard for Data Centers | Engineering360. Atlanta, GA, USA, 2016. $62 \mathrm{p}$.

[34] ISO/IEC-24764. Information technology - Generic cabling systems for data centres. Vernier, Geneva, Switzerland, 2015. 37 p.

[35] CENELEC-EN 50600-2-3. Information technology - Data centre facilities and infrastructures Part 2-3: Environmental control. Italy, 2015. $30 \mathrm{p}$.

[36] ANSI/BICSI-002. Data Center Design and Implementation Best Practices. USA, 2014. 500 p.

[37] ANSI/TIA-942. Telecommunications Infrastructure Standard for Data Centers. USA, 2005. 148 p. 